\title{
Effect of Cold Wet sheet Pack on Body Temperature among Healthy Individuals - Result of a Single Arm Study
}

\author{
Raj $\mathrm{RJ}^{*}{ }^{1}$, Birle PRA ${ }^{2}$ and Chaithanya ${ }^{2}$ \\ ${ }^{1}$ Dept. of Community Medicine, Sree Ramakrishna Medical College of Naturopathy and Yogic Sciences, \\ Kulasekharam, Kanyakumari district, Tamilnadu, India \\ ${ }^{2}$ Department of Hydrotherapy, Sree Ramakrishna Medical College of Naturopathy and Yogic Sciences, \\ Kulasekharam, Kanyakumari district, Tamilnadu, India
}

${ }^{*}$ Corresponding author: Raj RJ, B.N.Y.S, M.P.H, Asst. Professor, Dept. of Community Medicine, Sree Ramakrishna Medical College of Naturopathy and Yogic Sciences, Kulasekharam, Kanyakumari district, Tamilnadu, India 629161, Tel: +91 8220405193, E-mail: jainrajrussel@gmail.com

Citation: Raj RJ, Birle PRA, Chaithanya (2017) Effect of Cold Wet sheet Pack on Body Temperature among Healthy Individuals - Result of a Single Arm Study. J Obes Overweight 4(1): 101. doi: 10.15744/2455-7633.4.101

Received Date: October 27, 2017 Accepted Date: May 24, 2018 Published Date: May 26, 2018

\begin{abstract}
Introduction: Hydrotherapy, as the name suggests is the most ancient method of treating diseases by using water in its various forms. The use of water for therapy has been around for hundreds of years. The cold wet sheet pack is one of the common hydrotherapy techniques used for reducing body weight. There have been no documented studies conducted to scientifically evaluate this effect. This study is an attempt to examine the effect of cold wet sheet pack on body temperature. Application of cold wet sheet pack for particular duration increases the body temperature by utilization of calories thus may leads to reduction of bodyweight.

Materials and Methods: Thirty healthy volunteers were randomly selected from medical students enrolled in a naturopathic programme. The participants were of both sexes aged between 18 and 25 years under normal Body mass index (18.5-25). A cold $\left(20^{\circ} \mathrm{C} \pm 1^{\circ} \mathrm{C}\right)$ wet sheet pack has given to each of the participants for one hour duration. The outcome measures were resting blood pressure, body temperature and pulse rate.

Results: 30 Participants were successfully completed the study, all participants have shown a raise in body temperature after intervention which was statistically significant $(\mathrm{P}=0.003)$. There is no significant change in blood pressure and pulse rate. Also there was a week positive correlation between body mass index and body temperature.

Discussion: A cold wet sheet pack for one hour has shown a raise in body temperature, which indicate that the cold wet sheet pack have a role in reducing body weight by utilizing the calories. However, these observations are based on a short term single arm pre-post design on healthy students.

Conclusion: A cold wet sheet pack has been demonstrated in this study to have a significant effect in increasing body temperature and shows perspiration by utilization of calories. Large scale randomized control trials in obese patients over a longer period are warranted to conform the results which was uncovered in this study.
\end{abstract}

Keywords: Overweight; Obesity; Body temperature; Hydrotherapy; Calories utilization

\section{Introduction}

Hydrotherapy is one of the basic methods of traditional treatment widely used in the system of natural medicine, and this is the external or internal use of water in any of its forms (water, ice, steam) for health promotion or treatment of various diseases under various temperature, pressure, duration, and site. Many countries used to produce different physiological or therapeutic effects of hydrotherapy on different parts of the system for maintaining health, preventing, and treating the diseases [1]. The cold wet sheet pack is one of the common hydrotherapy technique traditionally used for reducing body weight. During the application of cold wet sheet pack, the sample undergoes a stage of cooling which last for 2 to 15 minutes followed by neutral stage where the cold wet sheet pack become equal to the body temperature, later it goes for heating and sweating stage [2].There have been no documented studies conducted to scientifically evaluate this effect. This study is an attempt to examine the effect of cold wet sheet pack on body temperature. Application of cold wet sheet pack for particular duration induces non shivering thermogenesis by utilization of calories thus may leads to reduction of bodyweight. 


\section{Materials and Methods}

\section{Setting}

The study was conducted at the department of hydrotherapy, Sree Ramakrishna medical college hospital for Naturopathy and yoga (SRKMCHNY) Tamil Nadu, India.

\section{Study participants}

300Students from the final year, third year and second year of the bachelor of naturopathy and yogic sciences (BNYS) programme at SRKMCNYS were screened and 30 students were randomly selected using simple random sampling separately for boys and girls. Healthy volunteers of both genders (males-15, Females-15) aged between 18 and 25 years were included in the study. Written consent was obtained from all the students and participation was voluntary. The study was approved by Institutional Ethics Committee of SRKMCNYS (approval no: 7-2/SRKMCNYS/IMR/IEC 19/2017-18).

\section{Intervention}

The cold wet sheet pack applied in our study includes the following procedure. $200 \mathrm{~cm}$ length and $137.5 \mathrm{~cm}$ breadth sized linen cloth was dipped in 5 liters of cold water at a temperature of $20^{\circ} \mathrm{C} \pm 1{ }^{\circ} \mathrm{C}$ measured using hydrometer (yellow capillaries mercury $-10+110 / 1^{\circ}$ ) and then the dipped Cloth was wrung provided that no water should be shed from the cloth. Earlier two woolen cloths sized about $217.5 \mathrm{~cm}$ in length and breadth of $162.5 \mathrm{~cm}$ was spread out in a couch lengthwise. At the inner ends (centre) of this we spread upon the cold water dipped cloth lengthwise so that outer layer is dry and inner layer is wet. The samples lie down upon the wet sheet in such a way that their shoulders should be few centimeters down to the upper edge of linen cloth (wet sheet). The samples raises both arms above his/her head while the attendants draw one side of the wet sheet across the body, turning it well up under the arms and tucking it in closely all along the side of the body. From the hips down, the edge of the sheet is tucked snugly around the leg of the corresponding side, leaving the other leg uncovered. The samples lowers his/her arm and holds them close by their side while the other side of the sheet is passed over and tucked in at the side and around the uncovered leg. A fold is made in the sheet over each shoulder so as to make it fit neck closely care being taken not to constrict the vessels. The body is thus completely and closely enveloped by the cold wet sheet. Then we applied a cold head compress to the participants. Next to this the outer dry woolen sheets were wrapped around the completely. The woolen cloth is next doubled under at the foot and the dry sheet at the head is brought around with a neat fold over each shoulder and tucked under the shoulder. The final step of the cold wet sheet pack has shown in Figure 1. The samples were under the pack for one hour duration up to sweating stage.

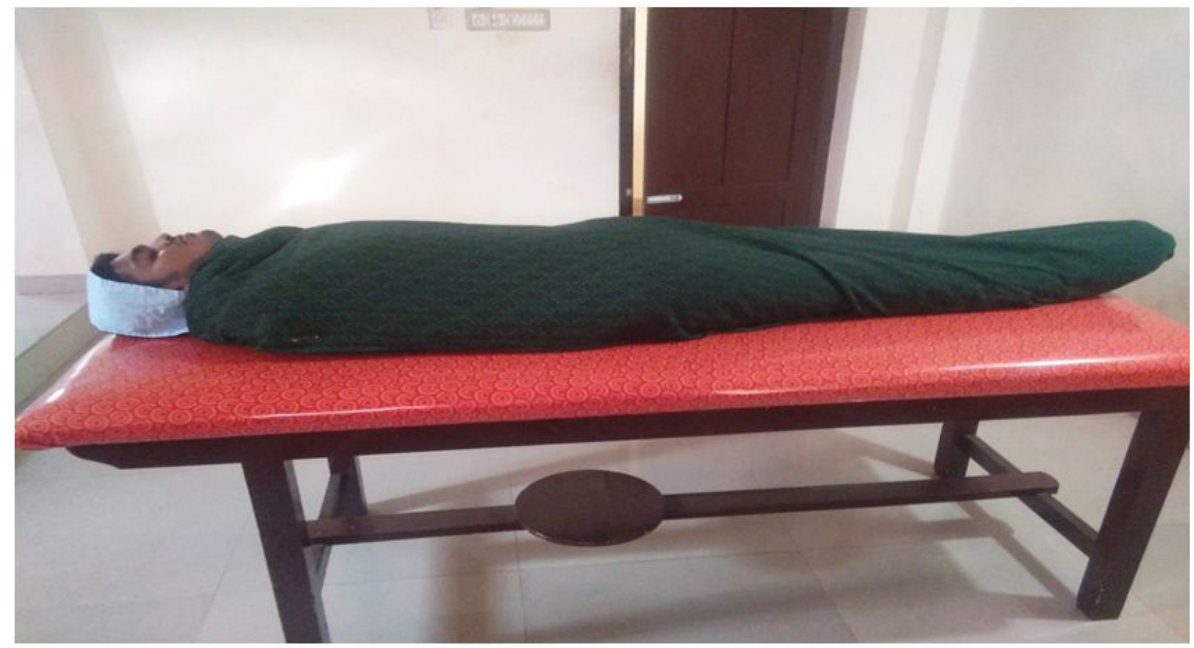

Figure 1: Cold wet sheet pack

\section{Outcome measures}

All the samples was assessed with measurements on body temperature using (omron) digital thermometer for a period of 1 minute at axilla .Blood pressure was measured using (DiamondregularIS3390) Sphygmomanometer and pulse rate by manual method before the intervention. Immediately after removing the cold wet sheet pack post interventional measurements of body temperature, blood pressure and pulse rate had taken. All the measurement had took in sitting positions and was taken by well trained naturopathy physician who have no other role in this study.

\section{Statistical method}

All the data was recorded in Microsoft excel 2007. Paired sample t test was done to determine the changes within the group and pearson correlation was done using spss software. 


\section{Results}

All participants who participated were aged between 18 to 25 years got completed the study (male $=15$, female $=15)$. There was a mean raise of $0.337^{\circ} \mathrm{C}$ body temperature $(\mathrm{p}=0.003$ ) observed after the treatment (pre temp $=36.253 \mathrm{SD} \pm .4599, \mathrm{post}-\mathrm{temp}=36.590$ $\mathrm{SD} \pm .3689)$. The paired difference within the group was significant $(\mathrm{p}=.003)$ for temperature. There is no statistical significance between systolic ( $\mathrm{t}-1.469$,sig 2 tailed.153) and diastolic (t-1.373,sig2tailed.180) blood pressure. Pulse rate also not showed any statistical significance (t1.652, sig 2 tailed.190) between pre intervention and post intervention. Table 1 shows the paired differences between the different measurements.

\begin{tabular}{|c|c|c|c|c|c|c|c|c|}
\hline \multirow{3}{*}{$\begin{array}{c}\text { Axilla } \\
\text { MEASUREMENTS }\end{array}$} & \multicolumn{5}{|c|}{ PAIRED DIFFERENCE } & \multirow{3}{*}{$\mathbf{T}$} & \multirow{3}{*}{ Df } & \multirow{3}{*}{$\begin{array}{l}\text { Sig.-(2- } \\
\text { Tailed }\end{array}$} \\
\hline & \multirow[t]{2}{*}{ MEAN } & \multirow[t]{2}{*}{$\begin{array}{l}\text { STANDARD } \\
\text { DEVIATION }\end{array}$} & \multirow[t]{2}{*}{$\begin{array}{c}\text { STANDARD } \\
\text { ERROR } \\
\text { MEAN }\end{array}$} & \multicolumn{2}{|c|}{$\begin{array}{c}\text { 95\% CONFIDENCE } \\
\text { INTERVAL OF } \\
\text { DIFFERENCE }\end{array}$} & & & \\
\hline & & & & LOWER & UPPER & & & \\
\hline PAIR-1 PRE-TEMP POST-TEMP & .3367 & .5629 & .1026 & .5469 & .1265 & --3.276 & 29 & .003 \\
\hline Pre- post sys bp & -3.000 & 11.188 & 2.043 & -7.178 & 1.178 & -1.469 & 29 & .153 \\
\hline Pre-dias bp post-dias bp & -3.067 & 12.236 & 2.234 & -7.636 & 1.502 & -1.373 & 29 & .180 \\
\hline Pre-pulse post-pulse & 2.600 & 8.621 & 1.574 & -.619 & 5.819 & 1.652 & 29 & .109 \\
\hline
\end{tabular}

A pearson product- moment correlation was run to determine the relationship between body mass index and body temperature after the intervention. There was a week positive correlation between body mass index and body temperature which was statistically insignificant $(\mathrm{r}=.265, \mathrm{n}=30, \mathrm{p}=.157)$. The correlation between body mass index and body temperature was tabulated in Table 2 and Figure 2 shows scatter plot. No adverse effects were reported by the participants.

\begin{tabular}{|c|c|c|c|}
\hline \multicolumn{2}{|r|}{ Correlations } & bmi & temp \\
\hline \multirow{5}{*}{ bmi } & \multirow{5}{*}{$\begin{array}{l}\text { Pearson Correlation Sig. (2-tailed) } \\
\text { Sum of Squares and Cross-products } \\
\text { Covariance } \\
\text { N }\end{array}$} & 1 & .265 \\
\hline & & & .157 \\
\hline & & 113.423 & 5.601 \\
\hline & & 3.911 & .193 \\
\hline & & 30 & 30 \\
\hline \multirow{5}{*}{ tem $p$} & \multirow{5}{*}{$\begin{array}{l}\text { Pearson Correlation Sig. (2-tailed) } \\
\text { Sum of Squares and Cross-products } \\
\text { Covariance } \\
\text { N }\end{array}$} & .265 & 1 \\
\hline & & .157 & \\
\hline & & 5.601 & 3.947 \\
\hline & & .193 & .136 \\
\hline & & 30 & 30 \\
\hline
\end{tabular}

Table 2: Pearson correlation between Body mass index and Body temperature

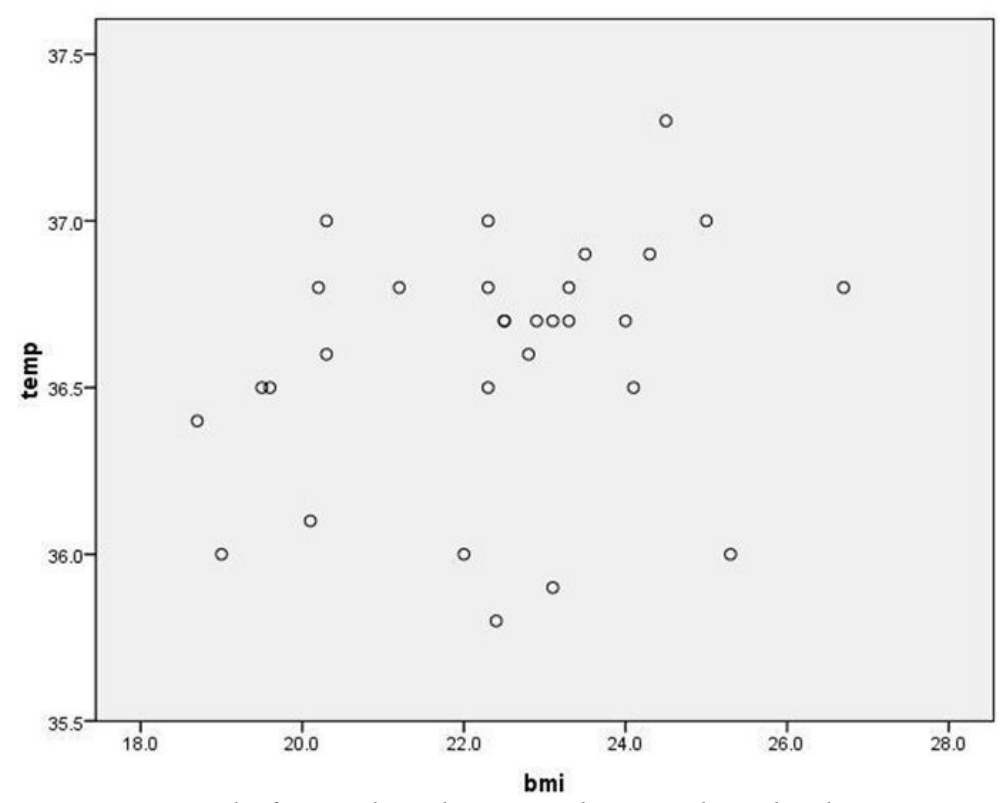

Figure 2: Scatter Plot for Correlation between Body Mass Index and Body Temperature 
However, the results of our study should be viewed in the context of several limitations. These observations are based on the single arm pre-post design, have no control group, examined in the person having normal body temperature. All the 30 members were showed a raise in body temperature.

\section{Discussion}

Hydrotherapy treatments are known to produce the local as well as the systematic healing effects upon the body. A cold wet sheet pack for one hour has shown a raise in body temperature in afebrile patients, which indicate that the cold wet sheet pack have a role in treating obesity. The possible mechanism behind the study may be due to action and reaction phase succeeding any hydriatic applications [2]. In mitochondria, the majority of protons re-enter through the ATP synthase, and the energy is used to synthesize ATP. If the protons re-enter by any other means, the mitochondria considerd to be uncoupled [3]. Electron transfer through the electron transport chain controls pumping of protons from the matrix to the inner membrane space, thus creating a proton motive force, whose energy is used by ATP synthase for the phosphorylation of ADP. Mitochondrial oxidative phosphorylation is not perfectly coupled to ATP synthesis, since a portion of energy is lost as heat instead of being converted in to ATP. Indeed, some of the energy present in the proton- motive force.

Dissipates as heat by the re-entry of $\mathrm{H}+$ in to matrix, through pathways independent of ATP synthase [4]. Brown adipose tissue, quickly and efficiently increases heat production by dissipating the mitochondrial proton motive force [5]. Wet sheet pack is one of the most effective of all means for quieting the general nervous system ,accomplished by lessening the blood supply of brain, slowing the respiration and heart beat, lessening the reflex irritability, increasing the quantity of lymph in the brain and supplying a condition essential for sleep [6]. During the last stage, perspiratory glands are so excited so that visible perspiration appears up on the brow. A great deal of vital work is performed not only up on the skin but by the nerve senders and internal viscera associated with it. Every cell in the body is stimulated to increase the action by elevation of temperature and the thermic impression made up on the whole skin surface. Under the influence of the elevated temperature the distraction and elimination of tissue toxin takes place with increased rapidity, heart beat is quickened, activity of the peripheral heart is also increased and the movement of blood in the vessels is also increased, bringing on an increased action of all the eliminative processes. There is increased oxidation of nitrogenous waste, thus the sweating pack is a strong reducing measure [7].

The elevation in temperature is itself responsible for speeding up metabolism [8]. The cold exposure triggers the irisin secretion in order to prompt the body to produce heat [9]. It has been suggested that activation of brown fat, during cold exposure, could be used to increase metabolic rate and thus reduce bodyweight [5]. It has been noted that each degree Celsius raise in body temperature is associated with a10-13\% increase in oxygen conception [8]. That is for every increase of $0.5 \mathrm{degree}$ Celsius in internal temperature of body, the BMR increases by about 7\% [10]. In our study there was a mean increase of .337 degree Celsius after cold wet sheet pack it shows that there must be $4.2 \%$ raise in basal metabolic rate .It reveals that there would be utilization of some amount of calories. Regular application of cold wet sheet pack for obese patient may be helpful in burning their calories thereby to reduce body weight. This study needs further research with big sample size and clinical trials to prove the desired effect.

\section{Conclusion}

A cold wet sheet pack has been demonstrated in this study to have a significant effect in increasing body temperature and shows perspiration by utilization of calories. Large scale randomized control trials in obese patients over a longer period are warranted to confirm the results which was uncovered in this study.

\section{References}

1. Mooventhan A, Nivethitha L (2014) Scientific evidence -based effect of hydrotherapy on various systems of the body. N Am J Med Sci 6: $199-209$.

2. John Harvey kellogg (2005) Traditional hydrotherapy ( $2^{\text {nd }}$ Edn) Published by National Institute of Naturopathy, Pune, India.

3. Nedergaard J, Ricquier D, Kozak LP (2005) Uncoupling proteins: current status and therapeutic, prospects. EMBO Rep 6: 917-21.

4. Busiello RA, Savarese S, Lombardi A (2015) Mitochondrial uncoupling proteins and energy metabolism. Front Physiol 6: 36.

5. Ravussin Y, Xiao C, Gavrilova O, Reitman ML (2014) Effect of intermittent cold exposure on brown fat activation,obesity,and energy homeostasis in mice. PLoS One 9: e85876.

6. Health by the Book (2017) H.E.A.L.T.H. by the book-Healing, Educating, and Advocating Lifestyles for Total Health, USA.

7. Mckie WL (1993) Scientific hydrotherapy, USA.

8. Barr DP, Du Bois EF (1918) The basal metabolismin malarial fever. Arch Intern Med 21: 627-58.

9. Lee P, Linderman JD, Smith S, Brychta RJ, Wang J (2014) Irisin and FGF21 are cold-induced endocrine activators of brown fat function in humans. Cell Metab 19: 302-9.

10. Stephens K (2017) How many calories does fever burns? USA. 


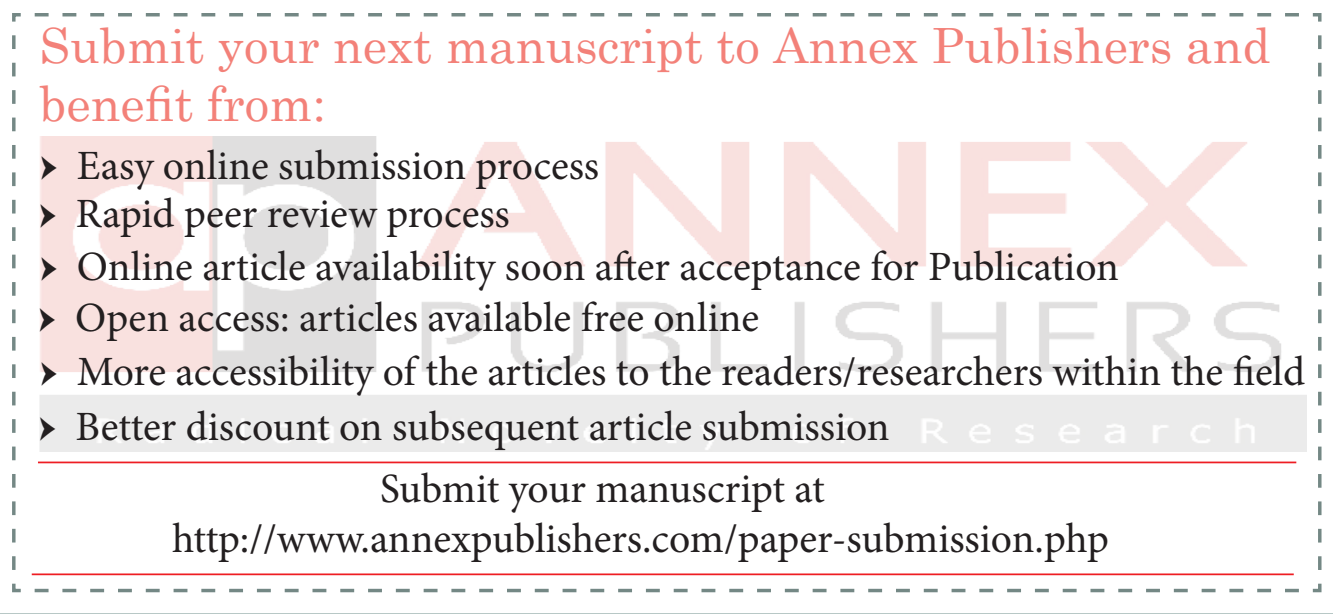

